\title{
El aporte literario y estético de The Beatles
}

\section{Gustavo Hernández Castro}

Licenciado en Estudios Latinoamericanos y en Filosofía. Máster en Administración de Empresas. Editor académico en la Universidad Estatal a Distancia. Dirección electrónica: ghernandezc@uned.ac.cr

\author{
Recibido: 27 de Octubre 2012 • Aceptado: 19 de Febrero 2013
}

\section{RESUMEN}

Este artículo intenta dilucidar el aporte literario y estético de la banda de rock and roll The Beatles a partir del reacomodo económico e ideológico moderno de la segunda mitad del siglo veinte. El punto de partida, para este análisis, es el pensamiento existencialista, específicamente las categorías del "absurdo", "ser" y la "nada", como conceptos de una espiral histórica en contradicción para nuestro tiempo.

Palabras clave: The Beatles, absurdo, contradicción, estética, existencialismo, ruptura, reconstrucción, ser, nada.

\section{ABSTRACT}

The literary and Aesthetic Contribution of "The Beatles". This last article tries to elucidate the literary and aesthetic contribution of the rock and roll band "The Beatles" from the modern economical and ideological rearrangement of the second half of the twenty century. The beginning point to start this analysis is the thought of the existentialism thought, specifically the categories of the "absurd", "being" and "nothing" as concepts of a historical helical as a contradiction for our future.

Key words: The Beatles, absurd, contradiction, Aesthetic, existentialism, rupture, rebuilding, being, nothing.

\section{Introducción}

\section{"Fuimos los primero cantantes de la clase obrera, que continuaron siéndolo y asi lo declaraban"}

\section{John Lennon}

Ringo, John, Paul y George nacían cuando las ciudades europeas eran bombardeadas por la aviación alemana. La ciudad de Liverpool no escapó a la desolación, destrucción y miedo social que suelen dejar las guerras a su paso. La localidad sufrió ochenta bombardeos, y destruyó la mitad de la infraestructura. También dejó 2500 fallecidos. Según Aracil, Oliver y Segura (1998: 16), Inglaterra tuvo aproximadamente 530000 víctimas en total.

Esta ciudad portuaria, cuya capital es Lancaster, tuvo su auge por la creciente industria textil del algodón y por ser un lugar de tránsito para el comercio internacional (segundo puerto más importante). 
Una de las principales riquezas que obtuvo este puerto fue producto del tráfico de negros (esclavos), cuyo destino era para el trabajo en las colonias de América.

Para el siglo diecinueve el $40 \%$ del comercio de Inglaterra pasaba por Liverpool. Sus principales productos de importación eran el azúcar, té, maderas, cuero, licor, café y tabaco. La ciudad se conocía en el mundo gracias a la calidad de sus exportaciones como el algodón, lana, lino, seda (industria textil), acero, cobre, bronces, cuchillería (industria metalúrgica). Debido a este auge comercial, la primera vía férrea de comunicación en Inglaterra fue la interconexión de las ciudades Liverpool y Manchester, en el año 1830.

Al finalizar la Segunda Guerra Mundial, el mundo se estaba reorganizando en un nuevo orden económico internacional. Los bolcheviques cumplían veintiocho años de haber tomado el poder (Revolución Rusa), en un país debilitado económicamente. Según Aracil, Oliver y Segura (1998: 16) la Unión Soviética tuvo la mayor cantidad de pérdidas humanas en la Segunda Guerra Mundial: 26 millones de personas; no obstante, el país estaba dispuesto a construir el reino de la libertad y la igualdad. De acuerdo con Marx (1976), "[...] de cada cual, según su capacidad; a cada cual, según su necesidad" (p. 15). Así, comenzaba oficialmente el enfrentamiento ideológico por controlar el reino de la necesidad en la Tierra.

Por su parte, Europa iniciaba la reconstrucción económica, moral, espiritual e ideológica. Sus ciudades estaban destruidas; su conciencia social desprovista de referentes morales sólidos, pero con un claro norte para rehacerse a partir del dolor de los otros (neocolonialismo), como mecanismo de acumulación de riquezas. Furtado (1978) le denomina a este fenómeno "la apropiación del excedente en la periferia" (p. 137).

El nuevo orden económico mundial resucita un concepto necesario de su marketing político, como variable axiomática para sostener su esquema social: el "humanismo" con contenidos simbólicos de "deshumanización". La persona convertida en mercancía, su valor humano, es la paga que recibe por su "esfuerzo". En otras palabras, vale por lo que vale su trabajo, vale por lo que trabajará mañana. No escapan a este constructo ideológico, obreros, campesinos, estudiantes, técnicos, artistas y académicos. Este concepto se desarrollará más adelante con la canción de Lennon (1998) "El héroe de la clase trabajadora".

La sociedad de la posguerra es la rebelión del ser y la nada. Sartre (1997) indicaba que, al oponerse la libertad individual, tratando de construirla socialmente, el ser humano escapa de sus responsabilidades y es condenado a comportarse como un fetiche: una cosa entre las cosas.

El ser, representado por la política colonial inglesa en recomposición, extiende algunas concesiones dadas a India en 1919. Recupera la antigua colonia alemana de África Oriental, logra unir una parte de la Unión Sudafricana con Rhodesia y, por otro lado, al Sudán anglo-egipcio con Egipto.

En 1931 se ratifica el Estatuto de Westminater que define la composición de la British Commonwealth of Nation (Comunidad Británica de Naciones, conformada por sesenta y cinco naciones, incluyendo las naciones de las Antillas de Barbolento y las dependencias de Australia).

En 1936, Inglaterra reconoce la independencia de Egipto y se compromete a retirar sus tropas que mantenía desde el año 1882. En el año 1954, ambos países llegan a un acuerdo final para el retiro de las tropas inglesas.

En 1947, Gran Bretaña declara la independencia de la India. Asimismo Birmania, en 1948, se determina república independiente.

Pero ¿cuáles fueron las circunstancias que impulsó a Inglaterra a conceder la independencia a esos países? Aunque las razones son múltiples, no fue porque este país creyera en la autodeterminación de los pueblos o por respeto a los movimientos autóctonos de liberación.

Carandell (2000), señala que "[...] la Segunda Guerra Mundial había debilitado económicamente a las potencias, representó una cesura. Las metrópolis habían perdido prestigio, algunas de ellas por la ocupación alemana (Francia, Bélgica, Países Bajos), otras por terminar como 
perdedoras (Italia, Japón) [...] fue los elevadísimos costes administrativos que representaban las colonias" (p. 18)

Adicionalmente, el gran ganador de la Segunda Guerra Mundial fue los Estados Unidos, donde el número de muertos fue significantemente inferior. Según Aracil, Oliver y Segura (1998), "Las bajas norteamericanas en todos los frentes, tanto en Pacífico como en Europa ascendieron a unos 385000 (de ellas, 45.000 correspondían a militares canadienses) que los demás países" (p. 16). Adicionalmente esta nación logró mediante los tratados firmados, facilitar préstamos a Europa, contribuyendo a incrementar la deuda económica de estos países con el nuevo imperio.

En este contexto histórico, las primeras seis décadas del siglo veinte, el occidente vuelca su reflexión (no únicamente) en corrientes de pensamiento filosófico existencialista. El existencialismo como tal, no es una escuela filosófica propiamente dicha, sino más bien una serie de posturas o pensamientos filosóficos, que pretenden plantear una posición diferente a las escuelas filosóficas tradicionales.

Una definición aproximada del existencialismo (Brugger, 1988) se circunscribe como una preocupación del ser humano acerca de cómo entender las cosas, en su relación consigo mismo y las posibilidades de libertad y autorrealización en este mundo.

De este modo, la nada, conformada por aquella generación de personas que construye la Europa destruida y la Inglaterra neocolonial, a partir del excedente de las periferias; contempla con ansiedad el mundo de los posibles o como lo definiría magistralmente Sartre (1983) "[...] cada uno debe superar su propia situación para estar en condiciones de transformar el mundo".

No obstante, Inglaterra no era la única conformación socioeconómica en reacomodo. Como se ha señalado, la Guerra Fría había intensificado, para ambos bandos (Este-Oeste), todos los mecanismos de dominación (explícitos e implícitos).

A esta etapa del devenir, Camus (1979) la llamaría "absurdo". En el mito de Sísifo, este filósofo llamaría la atención: "La hostilidad primitiva del mundo llega hasta nosotros a través de los milenios. Un segundo después no lo comprendemos ya, porque durante siglos solo hemos comprendido en él las figuras y los dibujos que poníamos previamente, porque en adelante nos faltan para emplear ese artificio. El mundo se nos escapa porque vuelve a ser él mismo". Este conflicto era entre seres humanos de buena voluntad luchando por la justicia y los valores versus el curso que tomaba el mundo privado de sentido, indiferente a ese ideal humano.

El progreso, la ciencia, sinónimos de conocimiento, se construyen a partir de la destrucción de los obstáculos que él mismo ha elaborado en su interpretación de la realidad. Estos obstáculos epistemológicos, son la contradicción continua del nuevo conocimiento que emerge del Ser y la Nada. Los siguientes hitos históricos de la década de los sesenta marcan lo real de la anterior afirmación:

- Independencia de África

- El ascenso del Opus Dei en España

- Francia: potencia nuclear

- Primera conferencia de los países no alineados

- El muro de Berlín: división de Europa

- La carrera espacial (URSS)

- Lo real maravilloso en la novelística latinoamericana

- La revolución cubana

- La crisis de los misiles (Cuba)

- El Concilio Vaticano II

- James Bond salva al mundo

- El Asesinato de John F Kennedy

- El primer enlace trasatlántico de TV

- El apartheid en Sudáfrica

- La intervención de Vietnam (Francia y Estados Unidos

- La Revolución Cultural (China)

- La Guerra de los Seis Días (Israel-Medio Oriente)

- La primera mujer astronauta al espacio (Valentina Tereshkova)

- La problemática interracial en Estados Unidos 
- El asesinato del Che Guevara (Bolivia)

- El asesinato de Martín Luther King

- La primavera de Praga (Intervención de la (URRS)

- La revuelta estudiantil de mayo en Francia

- El festival de Woodstock: la generación del amor

- La consolidación de dictaduras de derecha en América Latina

Estos fenómenos que nutrieron a las masas y estas, a su vez, al constructo cultural-ético en su conjunto, contribuyeron al nacimiento estético de nuevas generaciones, que no solo habían visto a sus antepasados morir en le defensa de la naturaleza humana, sino que estaban percibiendo que el exceso de corrientes materialistas y relativistas estaba alimentando a la modernidad.

\section{La construcción existencial del ser humano: el aporte literario y estético de The Beatles}

En este contexto existencial, The Beatles tienen la necesidad de expresar, en el ámbito musical, su propuesta estético literaria (influida por corrientes filosóficas existencialistas) que han marcado los cambios de mitad del siglo XX y lograr un distanciamiento epistemológico con los absurdos del ser humano, al proponer una reconstrucción del inconsciente colectivo y del imaginario social.

Si se debe definir una fecha simbólica para la preparación al salto estético y epistemológico, la podemos enmarcar un 1 de enero de 1962, cuando ellos se presentan en los estudios Decca de Londres para realizar una prueba de estudio.

Al respecto, Julia (1996) aporta datos más específicos que Davies (1968) y señala que "[...] The Beatles, interpretan quince canciones en total, entre ellas: "Till there was you", "Bésame mucho" $Y$ "The Sheik of Araby" (Julia, 1996: 57). Ese día Dick Rowe "tiene en sus manos el futuro del pop y lo deja volar" y le comenta al manager de esos jóvenes (Brian Epstein): "Haría usted mejor en dedicarse a su tienda de discos en Liverpool".

No obstante, esa experiencia les permite a los jóvenes músicos y a su manager incorporar una serie de cambios (imagen personal). Julia (1996) indica que Epstein impone transformaciones a nivel de vestimenta, peinados, comportamiento.

George Martín, como productor de la EMI, les concede el espacio para realizar las grabaciones y establece, como única condición, cambiar al baterista Pete Best, sustituido por Ringo Starr.

El 5 de octubre se publica el primer sencillo (45 rpm) de The Beatles con dos temas originales por el lado A, "Love me do" y por el B, "P.S. I love you", firmados por Lennon y McCartney. La edición constó de 100,000 mil copias, la canción del lado A, llega hasta el puesto diecisiete de las listas de venta en Inglaterra y presagia, de esta forma, la exitosa carrera musical de The Beatles.

Entre enero y setiembre de ese año, The Beatles continúan sus presentaciones locales, hasta que Epstein les procura una nueva oportunidad; primero, una prueba previa el 6 de junio con la Parlophone subsidiaria de la EMI y, posteriormente, el 11 de setiembre.

Para ilustrar ese contexto, a continuación, se transcriben unos fragmentos tomados de la $\mathrm{An}$ tología The Beatles (2003), narrados por los propios protagonistas:

Lennon: Recuerdo que teníamos que viajar a Londres en Noche Vieja. Tuvimos una sesión con Decca, una audición.

Harrison: Dick Rowe, el hombre que no quiso contratarnos, el presidente de Decca -dijo-, Sir. Epstein, los grupos con guitarras va a desaparecer $[. .$.$] que conocía a George Martín y$ le dijo a Brian que la llevase la cinta a él. Es cuando tuvimos la audición en Abbey Road.

Lennon: Tenía conocimientos y excelente educación musical (John, refiriéndose a George Martín).

Martin: Me pareció que tenían tremendo carisma. Sabía que eso era algo que les haría populares.

McCartney: Tuvimos una audición razonable, pero a él, no le gustó el batería.

Martin: Le dije a Brian Epstein que, cuando tuviéramos la próxima sesión, "no me quiero inmiscuir entre tú y el grupo, pero yo traigo el batería". 
MacCartney: Necesitábamos el mejor baterista de Liverpoll (refiriéndose a Ringo).

Harrison: Pero el hecho es que, según demostró la historia, Ringo era el cuarto miembro del grupo. Simplemente, tardó un poco más en aparecer en escena.

Starr: Era un miércoles cuando me llamó Brian. No recuerdo que John me llamara, aunque así aparece en algún libro. ¿Te unes al grupo? -Le pregunté- ¿qué quieres decir? -y me dijo-de manera permanente. Le dije que sí...

Martín: Cuando volvieron para la otra sesión, nadie me avisó que Ringo venía...

Starr: Fue un golpe terrible, iba dispuesto a tocar y tomaron a Andy White el batería profesional. Pero el viejo de George Martín se ha disculpado en varias ocasiones...

Epstein: Su primer disco tuvo un éxito. Love Me Do, vendió 100,000 mil copias.

La segunda fecha importante, simbólica y mítica es el 11 de setiembre de 1962 (Love me do, P.S.I Iove you) porque debido a su éxito local, la EMI, los reúne nuevamente un 11 de enero de 1963, para grabar las canciones "Please, Please Me" y "Ask Me Why" y el 22 de marzo de ese año, The Beatles en un solo día graban el LP titulado Please, Please Me.

Este álbum llega al primer lugar en la lista de ventas de Gran Bretaña y permanece por treinta semanas; se lanza un nuevo sencillo con las canciones "From me to you" y "Thank you girl", estas líricas repiten el mismo éxito comercial, pero como señala Julia (1996) "“...] lo más sensacional no son las ventas en sí mismas, sino la influencia disruptiva y liberadora que el conjunto de Liverpool está ejerciendo entre la juventud británica. Un efervescente soplo de libertad, un estallido de color iluminando, la gris y puritana sociedad inglesa surgida de la hambrienta posguerra" (p. 66).

Para ese momento, la banda ya había conquistado Inglaterra. Su percepción estética de la sociedad se modificaba y las constantes reflexiones críticas sobre la situación del ser humano en el mundo; maduraban.
Por ejemplo, en la presentación de la Royal Variety Show, comenta Lennon (Antología The Beatles, 2009), "Para el último tema, quisiera pedir su ayuda. La gente en el gallinero que dé las palmas y el resto puede hacer sonar sus joyas".

La gira a los Estados Unidos, marca el salto cualitativo de la banda El 7 de febrero de 1964, parten hacia ese país $y$, después de esta gira, The Beatles eran distintos, no solo conquistan en definitiva a Norteamérica, si no que la beatlemanía (término acuñado por el periódico Daily Mirror, del Reino Unido), se había impuesto en el mundo.

El imperio británico les otorgó el MIB (Miembros del Imperio Británico), no por su aporte a la cultura, sino más bien por el ingreso de divisas que representó para la economía inglesa.

Este premio, en particular, no le llamó la atención a Lennon. Brown (1991) señala que

John aborrecía la idea de recibir un MIB. La realeza y la estructura clasista de Inglaterra siempre había estado entre sus blancos favoritos, y la idea de sumarse a sus filas lo llenaban de airada culpabilidad [...] John fue menos diplomático. Los oficiales del ejército -dijo-reciben su premio por matar personas. Nosotros recibimos le nuestro por entretener [...] nos han dado el MIB por exportación, y la mención habría debido decir eso, si alguien hubiera recibido un premio por exportar millones de dólares en abono o maquinarias, todos habrían aplaudido ¿por qué a nosotros nos atacan? (p. 235).

Entre los años de 1963 y octubre de 1965, la banda habían grabado cinco LP: Please, Please Me (1963), With The Beatles (1963), A Hard Day Night (1964), Beatles For Sale (1964) y Help! (1965). Estos cinco primeros álbumes son la primera etapa, que da inicio a su maduración estética y literaria.

En octubre de 1965 inician la grabación de Rubber Soul, y termina en diciembre de ese año. Es el sexto álbum, donde The Beatles ya anuncian un cambio en su estilo musical (letras y acordes mejor elaborados). A partir de esta producción, las letras en su totalidad son compuestas por sus integrantes.

Sobre el álbum Rubber Soul, Ringo Starr y Paul McCartney mencionan: 
Starr: Nuestra actitud en general estaba cambiando. Habíamos madurado un poco (...) Nos estábamos extendiendo en todos los aspectos de nuestras vidas, abriéndonos a formas diferentes de pensar.

McCartney: cambiamos hacia canciones más surreales más distintas, había empezado a aparecer gente nueva que influyó en nosotros [...] (Antología The Beatles, 2003).

Canciones como "Norwegian Wood", "Im my life" y "Nowhere man" son temas existencialistas y marcan la postura y orientación filosófica de la banda.

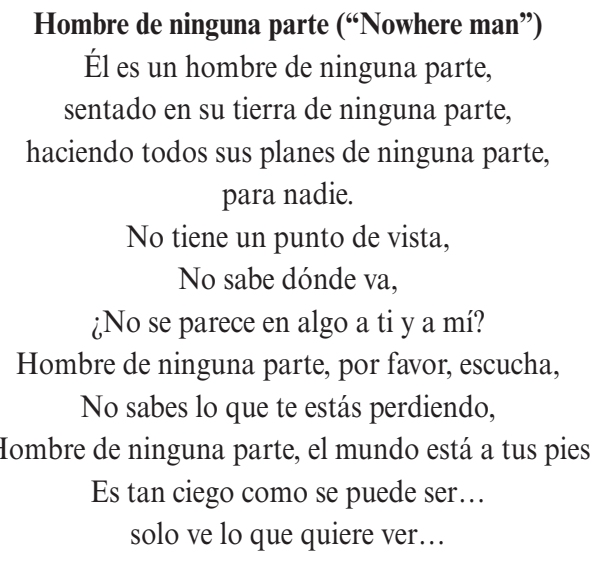

Rubber soul fue un álbum donde The Beatles desafiaron su propio concepto de creación musical proponiendo otras formas de acercamiento a la realidad a través de una introspectiva del mundo. El ser como conciencia del tener, como lo expresa la canción: "Hombre de ninguna parte, el mundo está a tus pies", implica además un acercamiento y distanciamiento del objeto "Déjalo todo, hasta que otro de eche una mano".

En este contexto, de objetos sociales imprecisos, The Beatles producen Revolver, que nos comunica que el mundo es uno solo (una totalidad). El ser ya no es metafísico, es un ente tangible, producto de la conciencia colectiva.

Las letras de las canciones son un esfuerzo para descubrir la verdad; proceso que se inicia con la objetivación y acercamiento de las partes de esa unidad, y que sin ella, no existiría la comprensión de la racionalidad humana.

Revolver fue la sétima producción de The Beatles. Es un disco conceptual, un tratado coherente que desarrollan historias breves pero con un alto contenido existencialista y de denuncia social.

Este LP se lanzó a la venta en Inglaterra, el 5 de agosto de 1966 y, en Estados Unidos, el 8 de agosto de ese mismo año. Combinó el rock ácido, psicodélico y el sinfónico. Está catalogado entre los cien mejores álbumes de todos los tiempos.

Canciones como "Tomorrow Never Knows", "Eleanor Rigby", "I'm Only Sleeping", "Taxman" y la metáfora de "Yellow Submarine" son expresiones estéticas de esa época de vivencias humanas de contradicción y ruptura:

Martin: El tema "Tomorrow Never Knows" salió en el álbum Revolver y era toda una innovación.

Lennon: Ese era yo en mi periodo tibetano [...] para suavizar un poco la letra que tenía una fuerte carga filosófica.

McCartney: Todos escuchábamos música clásica y otros estilos [...] (Antología The Beatles, 2003).

Una clara denuncia al sistema político de Inglaterra, lo encontramos en la canción "TaxMan":

\section{Recaudador de impuestos ("Taxman")}

Déjame explicarte como es el asunto: Uno para ti y diecinueve para mí,

Porque yo soy el recaudador de impuestos,

Si el cinco por ciento te parece poco,

Agradece que no te lo quite todo

Si conduces un auto, gravaré el camino,

Si intentas sentarte, gravaré tu asiento

Si tienen frio, gravaré tu calefacción

Si sales a dar un paseo, gravaré tus pies

No me preguntes para qué necesito el dinero

Si no quieres tener que pagar más.

Ahora mi consejo para los que mueren,

Declaren absolutamente todo

Y tú trabajas para mí 
El Estado, ese Leviatán, que se declara soberano, a partir del miedo social, necesita alimentarse (impuestos). Ya no solo del "excedente de la periferia", sino que desgarra a los propios ciudadanos para mantener sus instituciones, para darle seguridad, para garantizar la paz en tiempos de guerra, o para acudir a la guerra en procura de la paz.

Por su parte, el proyecto de realización de la existencia humana, Sartre (1997), encuentra su asidero en la metáfora del submarino amarillo "todos vivimos en un submarino amarillo"; o podemos decir, toda la humanidad habita en un solo mundo que necesitamos para ser libres:

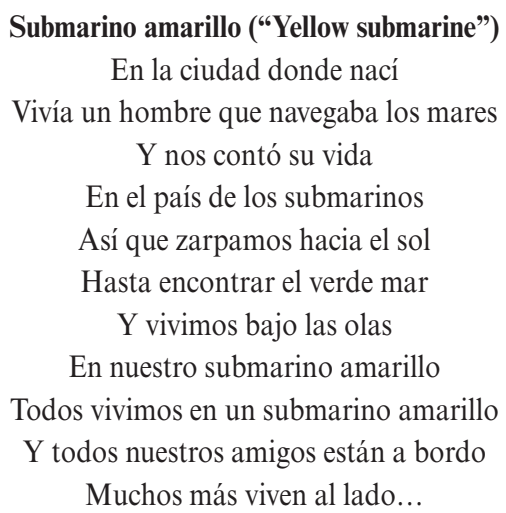

En contraposición con ese Estado que lo devora y lo quiere todo. El ser humano puede soñar y luchar con un mundo en que todas personas puedan convivir con todo lo que se necesita. Esta idea de pertenencia explora su esencia en el Ser; ese esfuerzo de la humanidad para estimular la rebeldía que en plena lucidez debe disminuir los sufrimientos y las injusticias. La metáfora del submarino amarillo es un optimismo del destino de la humanidad en confrontación con el miedo social.

En síntesis, las letras de Revolver no son consignas comerciales, sino propuestas para el cambio superestructural (hacer de la práctica social una praxis racional).

Durante el proceso de grabación de Revolver, Julia (1996), señala que "Lennon se sumerge en los libros de la psicología y psiquiatría moderna
(Sigmund Freud, Gustav Jung y Wilhelm Reich)" (pp. 87-88) y en temas religiosos. En una entrevista con Maureen Cleave (periodista del Evening Standard realizada el 4 de marzo de 1966), Lennon dice "El mensaje de Jesucristo, Mahoma y Buda es bueno. Es solo que la traducción ha sido equivocada".

Sgt. Pepper's Lonely Hearts Club Band salió a la venta en Inglaterra el 26 de mayo de 1967 y, en Estados Unidos, el 2 de junio de ese mismo año. Este álbum marca un salto cualitativo de la banda a nivel musical. Es la extensión magistral del Revolver en todas las fronteras existentes: estéticas, políticas e ideológicas. Transgrede la estructura misma de la sociedad capitalista moderna y anticipa un cambio de paradigma a nivel literario y musical.

Thompson (1967) señala

La cita para grabar el último álbum de The Beatles en los estudios EMI (Electrical and Musical Industries Limeted), es para las siete de la noche, pero los muchachos se han retrasado. De pronto, a las ocho, la sala se puebla de ruidos y animación. Paul McCartney llega canturreando una tonadilla cualquiera y lo sigue John Lennon. Ringo se presenta poco después y finalmente aparece George Harrison (p. 47).

Continúa el autor,

"En forma casi deliberada. The Beatles han echado por la borda la tradicional prudencia. Se están adelantando mucho a su público, grabando música tan compleja y tan distinta de la que los hizo famosos que bien podrían quedarse solos. Pero tal posibilidad no los inquieta en lo más mínimo" (Thompson, 1967: 47).

Brown (1991) alude a que

[...] las doce canciones del Sargent Pepper establecieron una nueva norma de realización en la música popular. Se tardó tan solo cuatro meses para grabarla a un costo de cien mil dólares. Al principio fue tan diferente y pasmosa de oír que, cuando Brian Wilson, de los Beach Boy, la escuchó por primera vez, dejó de trabajar en su próximo álbum, pensando que la quinta esencia del disco ya estaba hecha 
(...) The Beatles ascendieron de héroes pop a avatares y profetas (p. 308).

Los temas del álbum, tienen contenidos de denuncia social, reflexión filosófica e influencias literarias que desafían por completo las propuestas temáticas de las bandas de rock de esa época.

Posiblemente, la propuesta alternativa de esta producción, sea por lo que señala Thompson (1967:49): "De los cuatro, John, que tiene 26 años, es probablemente el más complicado (...) Lee copiosamente, desde Bertrand Russell, a Paul Tillich y Allen Ginsberg".

De este modo, canciones como una "Pequeña ayuda de mis amigos", la pertenencia del objeto subyace en el ser humano:

\section{¿Creerías en un amor a primera vista? \\ Sí, estoy seguro que pasa a todas horas. \\ ¿Qué es lo que ves cuando enciendes la luz? \\ No puedo decírtelo pero sé que es mío}

La totalidad del objeto se vuelve parte de la consciencia del sujeto; el relativismo y el perspectivismo, se derrumba ante la solides racional para encontrar la verdad entre el equilibrio del ser y el hacer. La canción, rompe con la herencia idealista que dominó el pensamiento occidental hasta de la década de los sesenta del siglo pasado, en el sentido, que las "cosas existen pero ellas las ignoran". Al afirmar la presencia del Ser en el acto mismo de la pertenencia: "No puedo decírtelo pero sé que es mío"

La canción "A day in the life", vincula al ser humano encarnado en la temporalidad de su existencia. Dos sujetos, con una misma existencia, y temporalidades distintas, denunciado según su verdad, la violencia y miedo de nuestra sociedad: por un lado, la victoria en la guerra, y por otro, una multitud volviendo la cara en señal de protesta.

Vi una película hoy, oh chico,

El ejército inglés acababa de ganar la guerra.

Una multitud volvió la cara,

Pero yo tuve que mirar...
La devoción, como categoría, de arraigó, que caracteriza a la humanidad, en contraposición a otras especies, marca su punto culminante cuando el ser humano ve más allá de su inmersión en la realidad, para darle un sentimiento, sentido para vivir y una esperanza.

Esta significación de sentido, no es mecánica o simple reflejo de los estímulos externos, como lo pretenden afirmar los teóricos conductuales. Nuestros sentimientos están comprometidos con el mundo, (en un proceso permanente de construcción y cambio), con las personas. La canción, "When I'm Sixty-Four", plantea la plena conciencia de la cotidianidad de los sentimientos para con las otras personas.

Cuando tenga sesenta y cuatro años ("When I'm Sixty-Four")

Cuando me haga viejo y se me caiga el pelo Dentro de muchos años....

¿Seguirás enviándome una tarjeta el Día de los Enamorados? ¿Me felicitarás el cumpleaños con una botella de vino?...

Saldríamos a pasear los domingos por la mañana

Cuidar el jardín, arrancar las malas hierbas....

Cuando tenga sesenta y cuatro años

En verano podríamos alquilar un chalet en la Isla de Wight Si no es demasiado caro...

Tendríamos que apretarnos el cinturón Los nietos en las rodillas... Vera, Chuck y Dave

Envíame una postal, escríbeme unas líneas Diciendo lo que piensas...

Finalmente, el diseño de la portada se puede interpretar como el renacer musical de la banda. Es la espiral dialéctica, es el pasado beatleriano que no volverá y la transformación hacia otro estadio más avanzado de su creación musical.

Esta espiral dialéctica no se circunscribe únicamente al cambio continuo de la banda; tiene que ver con la transformación de la historia. Para definirlo en términos filosóficos: tesis, síntesis y antítesis.

No es casualidad que en la portada del álbum, se haya ubicado fotos o figuras de personajes como los siguientes: 
Sir Robert Peel, Oscar Wilde, Carl Gustav Jung, Edgar Allan Poe, Karl Marx, Albert Einstein, John Bernard Saw o figuras colectivas como el anonymous como una representación de diferentes grupos de personas, sin organización definida, ni asociación, pero que convergen a determinadas protestas $\mathrm{y}$ otras acciones de carácter civil, político o cultural (anarquistas).

El Sgt. Pepper's Lonely Hearts Club Band marca el nuevo rumbo que toma la banda y que desea expresar a la sociedad postmoderna, en el sentido que la existencia social de los seres humanos, es la que determina la conciencia social e individual.

Este álbum no presenta un mundo tal y como lo hemos vivido y percibido que marcará el derrotero, a partir de sus propias contradicciones, mientras permite el surgimiento de una nueva humanidad y destruye el "absurdo" de la vieja sociedad.

Finalmente, es importante señalar, que la producción musical posterior al Sgt. Pepper's Lonely Hearts Club Band está constituido por cuatro álbumes, que resumen el ingenio y la creatividad de cuatro mentes que lograron captar la metáfora del ser humano en el devenir de la modernidad: "A través del universo".

Lennon fue más explícito. En su canción "Héroe de la Clase obrera", resume el peso existencial del ser humano, que carga con la miseria de una filosofía "el absurdo" que ha empobrecido al mundo con su destino y que cosifica al individuo utilizando un lenguaje inclusivo con teorías humanísticas, pero en su esencia excluyente.

Ya desde que naces hacen que te sientas pequeño porque no te dan tiempo en vez dártelo todo

hasta que el dolor es tan grande que no sientes nada Podrías ser un héroe de la clase obrera

Te hacen daño en casa y te pegan en la escuela Te odian si eres listo y te toman por loco

hasta que estás tan atontado que no entiendes nada

Podrías ser un héroe de la clase obrera

Después de veinte años de horror y tortura, se supone que has de elegir un trabajo

Pero ya no puedes funcionar del miedo que tienes

Podrías ser un héroe de la clase obrera

Te drogan con la religión, el sexo y la televisión

$\mathrm{Y}$ te crees ingenioso, apolítico y libre

Pero no eres más que un jodido ignorante

Podrías ser un héroe de la clase obrera

Te dicen que puedes llegar a la cima

Pero antes has de aprender a matar sonriendo

Si deseas triunfar como los de allá arriba

Podrías ser un héroe de la clase obrera

$\mathrm{Si}$ quieres ser un héroe, sígueme.

\section{Conclusión}

La influencia de pensamientos filosóficos, en la producción de The Beatles, es notaria. Las referencias bibliográficas consultadas confirman que los cuatros integrantes de la banda tenían conocimiento de esas corrientes, que sacudían al mundo de la postguerra.

No necesariamente todos los integrantes comulgaban con las mismas ideas. John, por ejemplo, había leído filosofía, literatura, psicología; George, era más místico, influido por la religión hinduista; Paul, más pragmático, con inclinación al arte moderno y la construcción estilista de las letras y la docta musical; Ringo con gustos por el sétimo arte.

Evidentemente por su posición de estrellas rock, estaban ligados a las diferentes personalidades que representaban esos pensamientos e ideales, de la época: políticos, poetas, escultores, filósofos, artistas de cine, periodistas; relaciones todas, que les dieron contacto con el conocimiento en sus diferentes perspectivas.

No obstante, cabe destacar la influencia de dos corrientes filosóficas, claramente identificables en las letras de estos dos álbumes. El existencialismo de Camus, por un lado, y el de Sartre por otro.

En Camus se evidencia el rompimiento del "absurdo", en el sentido de un conflicto trágico en la sociedad. Este filósofo afirmaba que era pesimista en cuanto al destino humano pero, al mismo tiempo, optimista en cuanto a su ser individual. Lo anterior, porque la humanidad 
es cautiva de sus propias verdades y, al reconocerlas, no puede alejarse de ellas y, más bien, debe enfrentarlas.

Reconocer las verdades, equivale a apropiarse del porvenir y de la esperanza; categorías exclusivamente humanas. Por ejemplo, esta pertenencia del sujeto mismo, se percibe en la letra de "Norwegian Wood", "me pidió que me quedara, me dijo que me sentara, miré a mi alrededor y no vi ninguna silla. Me senté en la alfombra esperando mi suerte".

Por su parte, la corriente sartriana en relación con la existencia que precede a la esencia; una libertad, "la nada", que se refugia en el corazón del ser humano y que obliga a las personas, a la humanidad hacerse, un lugar de Ser. En otras palabras, el mundo no es otra cosa que el espejo de mi libertad, de mi existencia y de la de los otros.

The Beatles muestran letras relacionadas entre sí de temas que tienen que ver con el inconsciente colectivo: la insensatez, el absurdo, el amor, la pertenencia, el distanciamiento del objeto, la devoción, la existencia o la transformación.

Categorías filosóficas que hacen al ser humano avanzar a un estadio de la belleza para transformarla en perfección. El pensamiento beatleriano, es una propuesta que le permite al género humano pasar de una metafísica al mundo de la conciencia crítica y al devenir de la razón.

Posiblemente The Beatles en su antítesis a su propia transformación y devenir, hayan parafraseado las palabras de Camus cuando dijo: "Mi obra está por delante de mí".

Quizás el legado de The Beatles para el siglo veinte y el nuevo, lo expuso McCartney mientras producían el Sgt. Pepper's Lonely Hearts Club Band, Thompson (1967): "[...] Pero no tiene objeto permanecer inmóviles [...] Hemos llegado a un punto en que no hay barreras. Musicalmente, ahora, en este instante, esta noche, nos encontramos en ese punto preciso" (p. 48).

The Beatles no inventaron la música, ni el rock and roll, pero hicieron algo que, en su tiempo, nadie había logrado: añadirle conciencia, filosofía y denuncia social a cada letra de sus canciones, principalmente, y posterior al álbum Rubber soul.

Tal vez, por esas razones, Lennon alguna vez señaló: "Mi rol en la sociedad, o el rol de un poeta o de un artista es tratar de expresar lo que todos sentimos. No decirle a la gente como se debe sentir. No como un jefe o como un líder, sino como una reflexión para todos nosotros"

El legado de estos músicos representa quizás esa huella del tiempo en nuestros días; contemplando el pasado, pensando que era bueno, pero The Beatles nos enseñaron que el futuro es mejor, porque sucede, mientras el presente trata de interpretar ese pasado.

\section{Bibliografía}

Aracil, R., Oliver J. y Segura, A. (1998), El mundo actual. De la Segunda Guerra Mundial a nuestros días. Barcelona: Edicions Universitat.

Brown, P. y Gaines, S. (1991), The Beatles. Buenos Aires: Javier Vergara.

Brugger, W. (1988), Diccionario de Filosofia. Barcelona: Herder.

Camus, A. (1979), El Mito de Sísifo. Buenos Aires: Losada.

Carandell, L. (2000), Nuestro Siglo: 1960-1969. Madrid: Plaza Janés.

Davis, H. (1968), “The Beatles", en Life en español, $n^{\circ}$. 10, Vol. 32.

Furtado, C. (1978), Prefacio a nueva economía política. México: Siglo Veintiuno.

Juliá, I. (1996), John Lennon. Madrid: La Máscara.

Lennon, J. (1998), Book. EE.UU: Capitol, Yoko Ono.

Marx, C., Engels, F. (1976), Critica del Programa de Gotha. Moscú: Progreso.

Sartre, J. (1983), Cahiers pour une morale. Paris: Gallimard.

Sartre, J. (1997). El existencialismo es un humanismo. San José: Guayacán.

Antología The Beatles (2003). London: Apple, Parlaphone, Abby Road.

Thompson, T. (1967), "The Beatles en órbita", Life en espa$\tilde{n} o l, \mathrm{n}^{\circ} 2$, Vol. 30 . 